\title{
Developing the history of unintentional injury: the use of coroners' records in early modern England
}

\author{
Elizabeth Towner, John Towner
}

27 August 1578. Peasmarsh, Hastings coroner: "About 7am on 12 August when Edmund Pette, aged over 8 months, was in a water-mill at Peasmarsh with Helen Pette, Helen went outside to shut "le fludegate" of the mill, leaving Edmund sitting in the mill near the watercourse. While Helen was outside, by misadventure Edmund fell into the watercourse and was drowned, dying immediately".

(Hunnisett 1996: Record 215). ${ }^{1}$

A tragic event, recorded by a coroner's inquest in Sussex, England, over 400 years ago. But why should this type of historical evidence be of any concern to researchers in the injury field today? First, there is the value of providing an historical perspective in any subject. Too often, the distant past is seen as a provider of the curious and the unusual; at best a distant echo of something we recognise today. Yet history is far more than that. The perspective of time provides depth and understanding that comes from seeing phenomena in continuous and constant change. It helps us sort out the essential elements of the subject from the transitory and we can see more clearly the dynamics of change and continuity. In some eras circumstances undergo rapid transformation, in others the pace of change is slow. Injury prevention however, lacks this perspective. Indeed, Cooter and Luckin have recently pointed out that "there is hardly a comparable subject in which historical investigation has been so meagre". ${ }^{2}$

Our second concern is to illustrate the value of using coroners' records in historical studies of injury. The above quotation reveals many of the essential elements that any researcher needs to understand a modern injury occurrence. As with any modern study, a fuller understanding comes from placing the event within the wider social, cultural, economic, political, and environmental context. We believe that coroners' inquests provide a rich source of information for historical research in the field of injury, but they have only rarely been used for work where injury has been the central concern. ${ }^{3}$ More usually, this material has been employed in studies of the history of suicide or murder, ${ }^{4-6}$ or for illuminating past lives in general. ${ }^{7-10}$

What follows is a short contribution towards the history of unintentional injury through an empirical case study. Using coroners' inquests as our primary source, we focus on one particular age group, children aged $0-14$ years and a particular geographical area and time period: the county of Sussex in England between the years 1485 and 1688 . We first set the scene by briefly describing the historical context of Sussex and the nature of the coroners' records. We then describe the broad patterns of injury death and the specific context within which the death occurred. We conclude by relating our findings to selected injury patterns gathered from coroners' records today.

\section{Historical context}

Under what social and geographical conditions were children carrying out their everyday lives in 16th and 17th century Sussex? This south eastern county was one of the more prosperous areas of England and, like most of the country, it was overwhelmingly rural in nature. Other activities included iron working in the High Weald and fishing and maritime trades along the coast, but most of the population lived in small village communities with few towns of any size. Chichester, Lewes, and Rye alone had populations over $1000 .{ }^{11}$ Within these communities, people lived in nuclear families. ${ }^{12}{ }^{13}$ High birth rates, accompanied by high death rates for children under 10 years old ${ }^{14}$ meant that family life was fragile and uncertain. Yet the parent-child relationship seems to have been as strong as in any age and former ideas of emotional indifference before the 18 th century are now widely questioned..$^{913}$ The mass of the population had a hard struggle for existence but children were cared for as much as conditions would allow.

\section{Coroners' records}

The coroners' inquests which we employ were part of the wider political and legal context of the time. A coroner's most important duty was the holding of inquests on homicides, suicides, unintentional injury, and all sudden and unexpected deaths in his area. ${ }^{16}$ An inquest was held as soon as possible after the incident occurred, before a jury of freeholders.

The information described here is from the surviving coroners' inquest reports for Sussex between 1485 and 1688. They have been translated verbatim by Hunnisett, ${ }^{17} 18$ with additional notes and information.

Clearly, the coroners' inquest records that we have used for this historical analysis have limitations. Their survival rate was not constant between 1485 and 1688 . We also have to consider the ways in which coroners operated in their areas. Stevenson ${ }^{19}$ and Cockburn ${ }^{20}$ have questioned whether seasonal variations in inquests can be partly related to the need to have enough cases to forward to the next round of the assizes.

Nevertheless, the records were generally compiled very soon after the event and provide a wealth of information on the circumstances surrounding the death. Hunnisett asserts that it is, "possible to be fairly confident that the narrative sections of the inquests faithfully reflect the jurors' 
findings". ${ }^{1}$ It is these narrative sections which gives the source its especial value: the accounts are immediate, vivid and often poignant, providing a window onto scenes which took place some 400 years ago. Furthermore, the ways in which the coroner and jurors attempted to understand the circumstances surrounding the death are framed within a cultural system which resonates with our own. The explanations are rational, assembling evidence from none other than the physical and human world. Certainly the governing classes (as represented by the coroner) would give no institutional sanction to explanations of accidents based on magic, witchcraft, diabolical possession, or other related beliefs. ${ }^{51}$

\section{General patterns of injury deaths}

Of the 1347 inquests of all forms of death for both adults and children, children under 15 years accounted for $178(13 \%)$. We found that 85 of these cases $(48 \%$, but involving 87 children), were concerned with unintentional injury deaths, $72(40 \%)$ involved murder, 13 $(7 \%)$ natural death, five (3\%) suicide, and three $(2 \%)$ causes of death were recorded as unknown.

Almost half of the unintentional injury deaths $(47 \%)$ involved children under 5 years old, while $20 \%$ were for $5-9$ year olds and $21 \%$ for 10-14 year olds. Male children were slightly more represented in the coroners' reports ( $53 \%$ of deaths) but although the male:female ratio was the same for the under $5 \mathrm{~s}$, the gap widened for the ages of 5-14 with the male:female ratio then becoming 63:37.

In terms of causes of unintentional injury death, drowning was by far the most common with $53 \%$ of all cases, followed by $17 \%$ hit/struck/crush injuries. Pedestrian road traffic injuries accounted for only $7 \%$ of deaths. This was followed by $6 \%$ for both falls in general and falls from a moving vehicle or horse. Very few children were killed in house fires (two cases) or by scalds and contact burns (three cases). Males and females were generally equally represented in the above types of injuries, but females were more affected by road traffic accidents. In terms of the main cause of death, drowning was heavily concentrated in children aged under 5 years.

The coroners' inquests often indicated the month of year and time of day of the incident. Most cases (70\%) occurred during the spring and summer months of March to August and most took place between $1 \mathrm{pm}$ and $5 \mathrm{pm}$. Very few incidents occurred during the hours of darkness.

We were also interested to see what activity the children were engaged in when they died and where the incidents took place. For many cases, the inquest gave no information on activity, but for 30 children, play was indicated and in nine cases the child was at work. In terms of location of the incident, $16 \%$ took place in the home, $29 \%$ immediately around the home, and 55\% were further afield. In the latter cases, however, we are fairly confident that virtually all were within the local area of the parish.

\section{Drownings}

As drownings formed the major type of injury and cause of death, we consider this area more fully. Water pits, generally just outside the home, were the main environment for drownings ( $26 \%$ of cases), followed by streams and rivers $(24 \%)$, generally located further afield. Other environments included wells, ditches, and ponds. Only two drownings took place within the home, both involving large water tubs. Differentiation by sex showed no clear pattern but when drowning was related to age group, then rivers, streams, and water pits were a major hazard for the 1-4 age group.

It is easy, now, to underestimate the amount of standing and running water in both rural and urban landscapes during this period. Ditches, streams, pits, ponds, uncovered wells and tubs, all exposed a child to the risk of drowning. It was in a later age that the desiccation of the landscape began, with water tamed and siphoned into covered drains, sewers, pipes, and pumps. Improved water supplies in towns began during the 17th century, but direct connections to houses were rare $^{1522}$ and the replacement of gravity fed systems by pumping did not take place on any scale until the $1680 \mathrm{~s}$ and $1690 \mathrm{~s}^{23}$ In rural areas, the improvements were more limited, even by the later 19 th century. ${ }^{24}$ The improvement in water supplies has been justifiably presented as an advance in combatting infectious diseases, ${ }^{25} 26$ but we also suggest that fewer child drownings were an unintended benefit.

\section{Accidents in the home}

Very few children died in house fires or from scalds and contact burns or poisoning. Only one house fire, involving two children, was recorded, a picture that is reflected in Hanawalt's medieval studies. ${ }^{8}{ }^{10}$ She, however, found a high rate of cradle fires among children under 1 year, suggesting exposure to open hearths. We found no cradle fires in our study, but a case of a 6 month old child left in a chair who fell into the fire (Hunnisett: record $107^{1}$ ). The low incidence of death from house fires may possibly be attributed to the small, single storey cottages in many of the villages from which rapid exit could be made ${ }^{27}$ and to the lack of noxious fumes produced. Overall, the home did not appear to be an especially dangerous environment, even for the under $5 \mathrm{~s}$, with only $16 \%$ of the child unintentional injury deaths occurring there (compared with $40 \%$ recorded in Levene's coroners' reports today ${ }^{28}$ ). Also, although people lived in a poorly lit world, we cannot detect evidence of injury deaths generated by the long hours of darkness.

\section{Accidents during work}

It was rare to find children who were involved in accidents during work (nine cases). The age at which children were expected to start work and perform more adult tasks was from about 8 to $13,{ }^{8}$ but work was limited. For girls, the jobs which led to unintentional injury deaths were mainly fetching water, either for their family, or 
in the case of a 12 year old, as a servant at an inn. A 14 year old girl was drowned washing linen in a river. For boys, the jobs were carters (9 years old and 12 years old), a sailor (13 years old), a ploughman (11 years old), and an agricultural worker aged 13. During this period, there does seem to have been the view that children would begin to learn tasks as preparation for adulthood before service or apprenticeship, but they were rarely expected to be independent workers. ${ }^{15}$

\section{Towns and traffic}

We also considered whether there was any distinctly "urban" context to injury deaths. Of the 10 incidents in Rye, seven in Chichester and five in Hastings, pedestrian road traffic accidents amounted to five. Only one other child pedestrian is recorded elsewhere in Sussex. Even though the numbers are very small, the pedestrian deaths show a strong urban cluster. The anecdotal evidence of individual cases provides evidence of urban streets as a danger. For instance, the girl playing with other children in Pallant Lane, Chichester, who was hit by a passing cart, or John Wright, aged 2 'playing with other children on 'le paviament' in Hastings who stumbled under the wheels of a passing wagon" (Hunnisett: record $494^{18}$ ). And in Rye, an infant was dropped by her young sister in the street "by the violent goinge of the horse and carte" (Hunnisett: record $25^{18}$ ). This builds on circumstantial evidence from other sources that roads in towns posed a real hazard to pedestrians. $^{23}$

\section{Supervision}

Supervision of a child at the time of the incident was rarely reported. This confirms other findings. ${ }^{23}$ In two cases, infants were with older children, who were not strong enough to prevent them being injured. Only three instances are cited of a lack of adult supervision. One concerns the infant who drowned in a water tub in the kitchen, while the two servants went outside to deal with a swarm of bees. A second, was the 6 month old child left by a servant when she went to milk a cow. Family circumstances would obviously make constant supervision difficult, as is evident in this third example. Luke, the 3 year old son of a widow in Hastings went out of the house, "without her knowledge to play around the water of the Bourne outside the town walls, accidentally fell in and was drowned by misadventure". Shortly afterwards, he was found by a small boy who fetched his mother and a neighbour who "took Luke out of the water but they were unable to restore him to life" (Hunnisett: record $64^{18}$ ).

\section{Preventive action}

We investigated whether the coroners in this period ever recommended any preventative action to be taken. (Even in the present day in the UK, the purpose of a coroner's court is not to collect information for epidemiological investigation or to suggest preventive action. ${ }^{29}$ In recent years Levene, ${ }^{28}$ Gaffney, ${ }^{29}$ Crilly, ${ }^{30}$ and Whittington ${ }^{31}$ in the UK and Moller, ${ }^{32}$ Stathakis and Scott, ${ }^{33}$ and Johnstone ${ }^{34}$ in Australia have explored the potential of coroners' data for providing reliable and accurate data to inform prevention.) We found no recommendations related to childhood injuries, but for an adult who, in 1487, fell over a cliff in a high wind, we learn that, "Because "le cliff' was crumbling and the cause of his death, the land near it has been marked off 3 feet towards the King's highway there" (Hunnisett: record $1^{17}$ ). Griffiths cites an inquest of 1658 in London, where wells and cellar hatches were required to be closed at night because they were, "very dangerous for children to fall in". ${ }^{13}$ In Holland during this period, carters and coachmen could be prosecuted if a child was hurt in a traffic accident. ${ }^{35}$ A Sussex coroner drew attention to the fact that a 3 year old child had been playing near "the uncovered draw-well of Richard Ellis of Hastings" (Hunnisett: record $498^{18}$ ).

The closest we come to any subsequent action related to children was in two cases in Rye in 1651 and 1655 where the drivers of carts were charged with murder after road traffic accidents. In one case, the child's mother preferred a bill of indictment against the driver after the following event:

"Between 3 and 4 pm or thereabouts on 8 Oct, when Elizabeth, daughter of Samuel Bunce of Rye, miller, was walking with another child in the common carriageway near the Landgate and Thomas Tutty's 'budge cart' drawn by 5 horses, was coming out of the gate, although George Breades, the carter, did all in his power to restrain them, the horses 'kept on their course' because of 'the descent of the ground there' and one of them knocked Elizabeth down and 'the offward wheele' of the cart by misadventure went over her head whereby she immediately died".

(Hunnisett: record $436^{18}$ ).

In both cases, the charges were reduced to manslaughter, partly, it appears, because neither driver attempted to leave the scene.

\section{Broad comparisons with patterns today}

Finally, we attempt to relate our findings to selected injury patterns today, gleaned from coroners' records, with the obvious caveat that directly comparing material from different historical eras can only be done with great caution. Some results are, however, strikingly similar. When we examine the age group involved, children under 5 years accounted for $47 \%$ of unintentional injury deaths in Sussex in 1485-1688, 54\% for selected English sources from $1984-88^{28}$ and $52 \%$ for Victoria, Australia from $1989-95 .{ }^{33}$ For 5-9 year olds, the figures are respectively $20 \%, 22 \%$, and $26 \%$ and for $10-14$ year olds $21 \%, 22 \%$, and $22 \%$. Sex ratios show some differences, however, with the Sussex data for 1485-1688 showing 53\% boys and $47 \%$ girls, compared with $67 \%$ boys and $33 \%$ girls for both the contemporary English and Australian data. This might suggest that, in the past, both sexes were more equally exposed to hazardous environments.

In terms of injury death types, when the Sussex data are compared with Levene's 
modern English data there are some striking changes. Most evident is the fact that while drownings have fallen from $53 \%$ of deaths to $6 \%$, pedestrian related unintentional injury deaths have risen from about $7 \%$ to $36 \%$. The road environment has replaced the water environment as the most hazardous place for children.

\section{Conclusion}

Our examination of coroners' inquests shows their potential for studying unintentional injury deaths in the past. We can obtain a vivid picture of children's everyday lives, how and where they played, helped with household chores, supervised younger children, and engaged in work. We can see how these activities on occasions led to their deaths. Between then and now, patterns of injury death have changed considerably. As yet, however, we are unable to identify the main eras of transformation of these patterns, for instance, when drownings began to decline as the main cause of unintentional injury death in children or how home and roads become more dangerous.

This study forms the first stage of more extensive research into changes in injury deaths in Sussex through periods of social, cultural, economic, political, and environmental change. Thus, we hope to be moving towards a greater understanding of unintentional injury deaths by placing them within a fuller and richer historical context.

1 Hunnisett R, ed. Sussex coroners' inquests 1558-1603. Kew: Public Record Office, 1996.

2 Cooter R, Luckin B. Accidents in history: injuries, fatalities and social relations. Amsterdam-Atlanta, GA: Rodopi, 1997.

3 Figlio K. What is an accident? In: Weindling P, ed. The social history of occupational health. London: Croom Helm, 1985

4 Anderson O. Suicide in Victorian and Edwardian England. Oxford: Clarendon Press, 1987.

5 MacDonald M, Murphy T. Sleepless souls: suicide in early modern England. Oxford: Clarendon Press, 1990.

6 Murray A. Suicide in the Middle Ages. Volume 1. The violent against themselves. Oxford: Oxford University Press, 1998.

7 Forbes T. By what disease or casualty: the changing face of death in London. In: Webster C, ed. Health, medicine and mortality in the sixteenth century. Cambridge: Cambridge University Press, 1979. 8 Hanawalt B. Child rearing among the lower classes of late
medieval England. fournal of Interdisciplinary History 1977; viii: $1-22$.

9 Hanawalt $\mathrm{B}$. The ties that bound: peasant families in medieval England. Oxford: Oxford University Press, 1986.
Enalien

10 Hanawalt B. Growing up in medieval London: the experience of childhood in history. Oxford: Oxford University Press, 1993.

11 Patten J. English towns, 1500-1700. Folkestone: Dawson, 1978.

12 Anderson M. Approaches to the history of the western family 1500-1914. Cambridge: Cambridge University Press, 1980.

13 Griffiths P. Youth and authority: formative experiences in England 1560-1640. Oxford: Clarendon Press, 1996.

14 Schofield R, Wrigley E. Infant and child mortality in England in the late Tudor and early Stuart period. In: Webster $\mathrm{C}$, ed. Health, medicine and mortality in the sixteenth century. Cambridge: Cambridge University Press, 1979.

15 Pelling $M$. The common lot: sickness, medical occupations and the urban poor in early modern England. London: Longman, the urban.

16 Hunnisett R. The medieval coroner. Cambridge: Cambridge University Press, 1961

17 Hunnisett R, ed. Sussex coroners' inquests 1485-1558. Lewes: Sussex Record Society, 1985

18 Hunnisett R, ed. Sussex coroners' inquests 1603-1688. Kew: Public Record Office, 1998.

19 Stevenson S. The rise of suicide verdict in south-east England, 1530-1590: the legal process. Continuity and Change 1987;1:37-75.

20 Cockburn J. Early modern assize records as historical evidence. Fournal of the Society of Archivists 1975;5:215-31.

21 Thomas K. Religion and the decline of magic. London: Weinderfeld \& Nicholson, 1971 .

22 Mayhew G. Tudor Rye. Falmer: University of Sussex, 1987.

23 Jones E, Falkus M. Urban improvement and the English Jones E, Falkus $M$. Urban improvement and the English Borsay P, ed. The eighteenth-century town. London: Longman, 1990 .

man, 1990.
24 Mingay G. The rural slum. In: Gaskell M, ed. Slums. Leicester: Leicester University Press, 1990

25 Dobson M. Contours of death and disease in early modern England. Cambridge: Cambridge University Press, 1997.

26 Rosen G. A History of public health. Baltimore: Johns Hopkins University Press, 1993.

27 Barley M. Rural housing in England. In: Thirsk J, ed. The agrarian history of England and Wales. Cambridge: Cambridge University Press, 1967: 1500-640.

28 Levene S. Coroners' records of accidental deaths. Arch Dis Child 1991;66:1239-41.

29 Gaffney B. Use of coroner's reports for surveillance of accidental death. F Public Health Med 1993;15:272-6.

30 Crilly $M$. Contributory factors to traffic accident deaths Crilly M. Contributory factors to traffic accident deaths
identified at coroner's inquests. $\mathcal{f}$ Public Health Med

31 Whittington R. Alcohol-related deaths: Birmingham coroner's records. BMF 1982;284:1162.

32 Moller J. Coronial information systems: needs and feasibility study. Adelaide: National Injury Surveillance Unit, 1994.

33 Stathakis V, Scott G. Coronial data: a comprehensive overview. HAZARD: Victorian Injury Surveillance System 1999;38:1-13.

34 Johnstone $\mathrm{G}$. The role of law in injury prevention. In: Ozanne-Smith $\mathrm{J}$, Williams $\mathrm{F}$, eds. Injury research and prevention: a text. Melbourne, Australia: Monash University Accident Research Centre, 1995.

35 Schama S. The embarrassment of riches: an interpretation of Dutch culture in the golden age. London: Collins, 1987. 